\title{
The CD38-cyclic ADP-ribose signalling system in insulin secretion: molecular basis and clinical implications
}

\author{
H. Okamoto, S. Takasawa, K. Nata \\ Department of Biochemistry, Tohoku University School of Medicine, Sendai, Japan
}

In answer to the comments of Islam and Berggren concerning our hypothesis on the CD38-cyclic ADPribose (cADPR) signalling system, we will present several lines of evidence that we believe can explain the discrepancies between their view and ours.

\section{The Okamoto model and $c A D P R$}

Glucose is the primary stimulus of insulin secretion and synthesis in pancreatic beta cells of the islets of Langerhans [1-3]. Increases in the intracellular $\mathrm{Ca}^{2+}$ concentration mediate the biochemical events that couple glucose stimulation to insulin secretion, and mobilization of $\mathrm{Ca}^{2+}$ from intracellular stores in the endoplasmic reticulum as well as $\mathrm{Ca}^{2+}$ influx from extracellular sources are important in this process [4]. Concerning the mechanism of $\mathrm{Ca}^{2+}$ influx from extracellular sources, it has been proposed that ATP generated in the process of glucose metabolism inhibits the ATP-sensitive $\mathrm{K}^{+}$channel, causing beta cell membrane depolarization, thereby opening the voltagedependent $\mathrm{Ca}^{2+}$ channel and resulting in $\mathrm{Ca}^{2+}$-influx from the extracellular space [5]. However, it was thought that inositol 1, 4, 5-trisphosphate $\left(\mathrm{IP}_{3}\right)$ is a

Corresponding author: Professor H. Okamoto, Department of Biochemistry, Tohoku University School of Medicine, 2-1 Seiryo-machi, Aoba-ku, Sendai 980-77, Miyagi, Japan

Abbreviations. cADPR, cyclic ADP-ribose; $\mathrm{IP}_{3}$, inositol 1, 4, 5trisphosphate; RyR, ryanodine receptor $\mathrm{Ca}^{2+}$ channel; RTPCR, reverse transcription polymerase chain reaction; RIA, radioimmunoassay; FSBA, 5'-p-fluorosulfonylbenzoyladenosine; KIC, $\alpha$-ketoisocaproate; BST-1, bone marrow stromal antigen 1; PCR, polymerase chain reaction; SSCP, single stranded conformation polymorphism; FKBP12, FK506-binding protein 12; FKBP12.6, FK506-binding protein 12.6; CaM kinase II, $\mathrm{Ca}^{2+} /$ calmodulin-dependent protein kinase II; CICR, $\mathrm{Ca}^{2+}$-induced $\mathrm{Ca}^{2+}$ release; IDDM, insulin-dependent diabetes mellitus. second messenger for $\mathrm{Ca}^{2+}$ mobilization from intracellular stores [6]. Since 1981, we have proposed a model for beta cell damage and its prevention as shown in Figure 1; that is, diabetogenic agents such as streptozotocin and alloxan damage DNA, activating poly(ADP-ribose) synthetase which uses $\mathrm{NAD}^{+}$ as a substrate $[2,7-12]$. Consequently, intracellular levels of $\mathrm{NAD}^{+}$fall dramatically, causing the inhibition of cellular functions such as insulin synthesis and secretion, and the beta cell ultimately dies. Although insulin-dependent diabetes mellitus (IDDM) can be caused by many different agents such as immunologic abnormalities, inflammatory tissue damage and betacytotoxic chemical substances, the final pathway for the toxic agents is the same, as shown in Figure 1. Therefore, IDDM is theoretically preventable by suppressing immune reactions, scavenging free radicals, and inhibiting the poly (ADP-ribose) synthetase by nicotinamide and 3-aminobenzamide. The question then arises as to why maintaining the cellular NAD ${ }^{+}$ level is essential for beta cells to secrete and synthesize insulin. Since 1987, a metabolite of $\mathrm{NAD}^{+}$, cADPR, has been reported to be as potent and powerful a releaser of intracellular $\mathrm{Ca}^{2+}$ as $\mathrm{IP}_{3}$ in a variety of cells [13-29]. In 1993, we found that the cADPR level increased in pancreatic islets in response to glucose stimulation and that cADPR released $\mathrm{Ca}^{2+}$ from the microsomes, suggesting that cADPR has a second messenger role in insulin secretion [15]. Furthermore, we found that the cADPR level was not increased by glucose stimulation in pancreatic islets pretreated with streptozotocin [15]. When poly(ADP-ribose) synthetase inhibitors such as nicotinamide and 3aminobenzamide were present, the cADPR level increased with glucose stimulation even in the presence of streptozotocin. These results suggest that cADPR is synthesized from $\mathrm{NAD}^{+}$by glucose stimulation in beta cells $[12,15]$. We have thus proposed another pathway, the CD38 (ADP-ribosyl cyclase/cADPR 


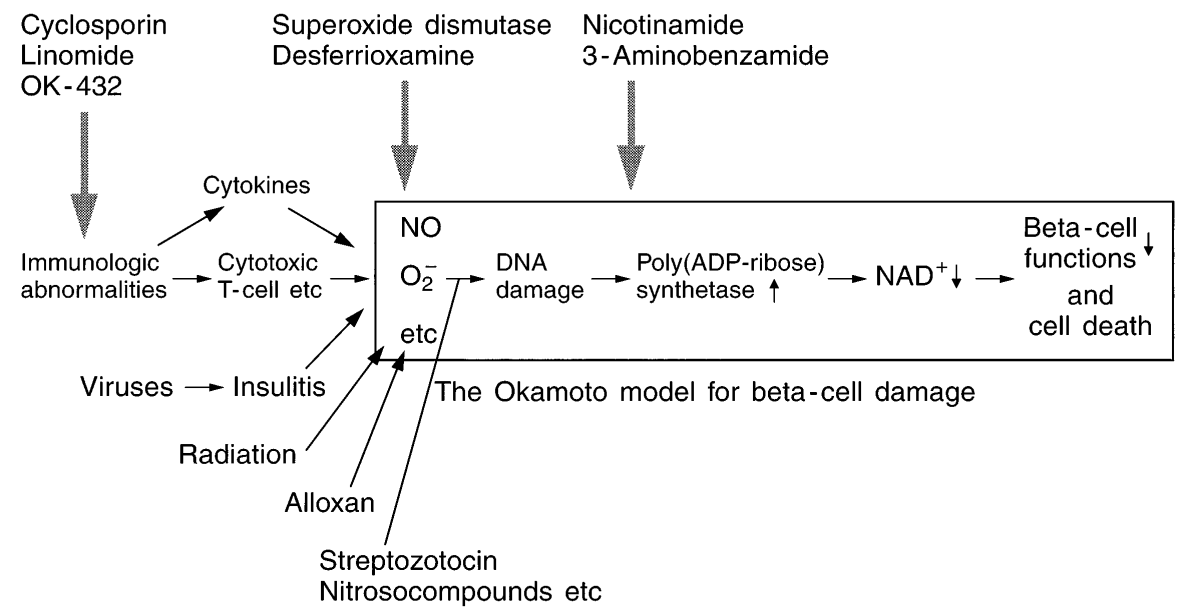

Fig. 1. A unifying model for beta-cell damage and its prevention in toxin- or virus-induced and immune diabetes (The Okamoto model) (adapted from [11,30]). Although IDDM can be caused by many different agents such as immunologic abnormalities, inflammatory tissue damage, alloxan and streptozotocin, the final pathway leading to beta-cell damage is the same. This pathway involves the generation of free radicals, DNA damage, nuclear poly (ADP-ribose) synthetase activation and $\mathrm{NAD}^{+}$depletion. The fall in cellular NAD ${ }^{+}$inhibits the cellular functions such as insulin synthesis and secretion, and the betacell ultimately dies. Therefore, the beta-cell damage is theoretically preventable through inhibition of the serial reactions, as indicated by shaded arrows. One method is by inhibiting abnormal immune reactions with immunomodulators such as cyclosporin, linomide and OK-432 [68,69]. Others are scavenging the radicals, which break DNA, by superoxide dismutase and other radical scavengers and inhibiting the poly (ADP-ribose) synthetase by specific inhibitors such as nicotinamide and 3 -aminobenzamide to prevent the decrease in the $\mathrm{NAD}^{+}$level

hydrolase) - cADPR signal system, for the increase in the intracellular $\mathrm{Ca}^{2+}$ concentration for insulin secretion by glucose in pancreatic beta cells $[15,30,31]$ : millimolar concentrations of ATP, generated in the process of glucose metabolism, induce cADPR accumulation in beta cells by inhibiting the cADPR hydrolase activity of CD38 [32-34], and cADPR then acts as a second messenger for intracellular $\mathrm{Ca}^{2+}$ mobilization from the endoplasmic reticulum for insulin secretion [15, 22, 35, 36] (Fig. 2).

\section{$\mathrm{Ca}^{2+}$ release by cADPR from islet microsomes}

We have established a method for isolating large numbers of islets from pancreases, and the handpicked islets after the collagenase digestion were shown to retain fully the functions of insulin secretion and synthesis in response to glucose stimulation [2]. We examined the release of $\mathrm{Ca}^{2+}$ from rat pancreatic islet microsomes and found that cADPR induced $\mathrm{Ca}^{2+}$ release from islet microsomes but $\mathrm{IP}_{3}$ did not

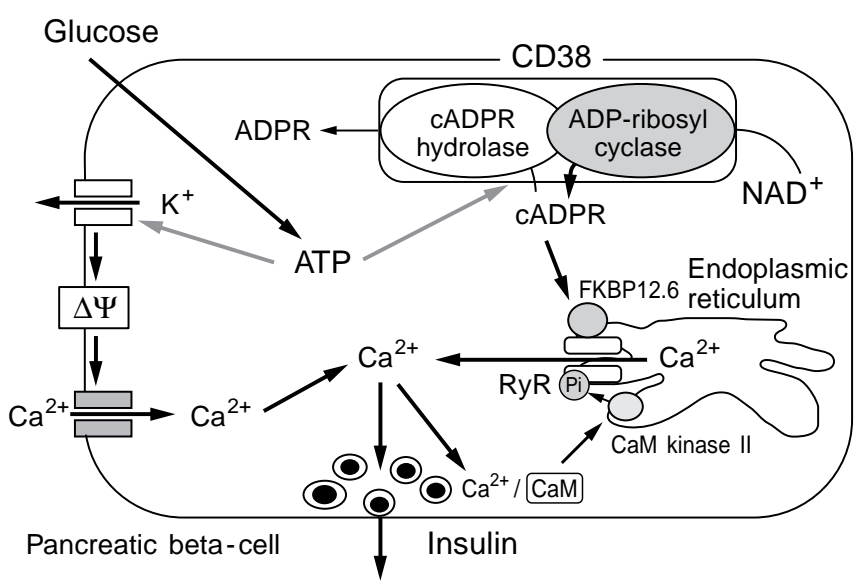

Fig. 2. Insulin secretion by glucose stimulation in beta cells (adapted from [36]). The insulin secretion via the CD38cADPR signalling system as described in this paper is shown on the right. cADPR binds to FKBP12.6 to release $\mathrm{Ca}^{2+}$, dissociating FKBP12.6 from RyR [35]. CaM kinase II phosphorylates RyR to sensitize and activate the $\mathrm{Ca}^{2+}$ channel ( $P i$, phosphorylation of RyR by CaM kinase II) [22]. $\mathrm{Ca}^{2+}$, released from intracellular stores and/or supplied from extracellular sources, further activates CaM kinase II and amplifies the process. In this way, $\mathrm{Ca}^{2+}$-induced $\mathrm{Ca}^{2+}$ release (CICR) can be explained. The conventional insulin secretion mechanism by $\mathrm{Ca}^{2+}$ influx from extracellular sources $[5,70]$ is shown on the left. ADPR, ADP-ribose

[15]. In rat cerebellum microsomes, both cADPR and $\mathrm{IP}_{3}$ induced $\mathrm{Ca}^{2+}$ release, and heparin, an inhibitor of $\mathrm{IP}_{3}$ binding to its receptor, blocked only the $\mathrm{IP}_{3}$-induced $\mathrm{Ca}^{2+}$ release [15]. These results indicate that cADPR is effective in $\mathrm{Ca}^{2+}$ release from islet microsomes. In contrast, in cerebellum microsomes, both cADPR and $\mathrm{IP}_{3}$ induce $\mathrm{Ca}^{2+}$, but the mechanisms of $\mathrm{Ca}^{2+}$ release and/or the $\mathrm{Ca}^{2+}$ pools appeared to be different from each other.

Some controversial results have been reported using diabetic beta cells such as $o b / o b$ mouse islets and RINm5F cells [37-39]. We have recently examined the $\mathrm{Ca}^{2+}$ releasing activity of these diabetic beta cell microsomes, compared it to that of the 
microsomes of normal beta cells such as C57BL/6J mouse islets, and found that the $\mathrm{Ca}^{2+}$ release responses of these diabetic beta cell microsomes were quite different from those of normal islet microsomes [36]. Microsomes from C57BL/6J mouse islets as well as Wistar rat islets released $\mathrm{Ca}^{2+}$ in response to cADPR but scarcely in response to $\mathrm{IP}_{3}$. This response to cADPR was completely attenuated by the prior addition of $100 \mathrm{nmol} / \mathrm{l} 8$-amino $\left(\mathrm{NH}_{2}\right)$-cADPR, an antagonist of cADPR $[29,40]$. In contrast to normal islet microsomes, $o b / o b$ mouse islet microsomes released only a small amount of $\mathrm{Ca}^{2+}$ by cADPR but released more $\mathrm{Ca}^{2+}$ by $\mathrm{IP}_{3}$. RINm5F cell microsomes responded well to $\mathrm{IP}_{3}$ to release $\mathrm{Ca}^{2+}$ but did not respond to cADPR. The $\mathrm{Ca}^{2+}$ releases by $\mathrm{IP}_{3}$ in $o b / o b$ mouse islets and RINm5F microsomes were attenuated by the prior addition of $100 \mu \mathrm{g} / \mathrm{ml}$ heparin and the small $\mathrm{Ca}^{2+}$ release response to cADPR observed in $o b / o b$ islet microsomes was also attenuated by the prior addition of $8-\mathrm{NH}_{2}$-cADPR. These results together with the finding that $o b / o b$ mouse beta cells and RINm5F cells released $\mathrm{Ca}^{2+}$ in response to $\mathrm{IP}_{3}$ but scarcely in response to cADPR by patch clamp experiments [37-39] strongly suggest that cADPR acts as a second messenger for $\mathrm{Ca}^{2+}$ mobilization from intracellular stores in normal beta cells and that the $\mathrm{Ca}^{2+}$ release machinery by cADPR may be replaced with that by $\mathrm{IP}_{3}$ in diabetic beta cells.

Moreover, concerning intracellular $\mathrm{Ca}^{2+}$ release channels, the mRNA expression of the type 2 ryanodine receptor (RyR-2), which is postulated to be a $\mathrm{Ca}^{2+}$ release channel for cADPR [35,41], was clearly detected in normal mouse (C57BL/6J) islets but not in $o b / o b$ mouse islets by reverse transcription-polymerase chain reaction (RT-PCR). In contrast, $\mathrm{IP}_{3}$ receptor $\left(\mathrm{IP}_{3} \mathrm{R}-1, \mathrm{IP}_{3} \mathrm{R}-2, \mathrm{IP}_{3} \mathrm{R}-4\right.$ and $\left.\mathrm{IP}_{3} \mathrm{R}-5\right)$ mRNAs were not detected in normal islets but were clearly detected in $o b / o b$ islets, and although $\mathrm{IP}_{3} \mathrm{R}-3 \mathrm{mRNA}$ was slightly detected in normal islets, the mRNA expression was significantly increased in $o b / o b$ islets. The expression of $\mathrm{IP}_{3} \mathrm{R}-3$ in normal rat islets and its increased expression in RINm5F cells have also been reported [42]. These changes in the gene expression of intracellular $\mathrm{Ca}^{2+}$ release channels fit well with the observation that $\mathrm{IP}_{3}$-induced $\mathrm{Ca}^{2+}$ mobilization preferentially works in $o b / o b$ islet and RINm5F cell microsomes. From these results, it is possible that changes in the gene expression involved in intracellular $\mathrm{Ca}^{2+}$ mobilization occur in diabetic beta cells, resulting in an abnormal response to glucose.

\section{cADPR accumulation in islets in response to glucose stimulation}

The next important issue is whether the accumulation of cADPR is actually caused by glucose stimulation in pancreatic islets. Recently, we incubated normal rat
(Wistar) islets with 2.8 and $20 \mathrm{mmol} / \mathrm{l}$ glucose, and assayed the cADPR content in the islets by radioimmunoassay (RIA) using an anti-cADPR antibody $[36,43]$. The cADPR content of islets incubated with $20 \mathrm{mmol} / \mathrm{l}$ glucose was increased within $5 \mathrm{~min}$, whereas the cADPR content of islets incubated with $2.8 \mathrm{mmol} / \mathrm{l}$ glucose was not. The results were consistent with our previous observation based on the $\mathrm{Ca}^{2+}$ releasing activity of islet extracts [15]. Malaisse et al. [44] measured the cADPR content in rat islets and reported that it appeared not to be significantly affected by glucose. In our experiments, fasting of rats before isolation of the islets and the usage of Hanks solution containing $2.8 \mathrm{mmol} / \mathrm{l}$ glucose during the islet isolation may account for the rapid and significant increase of the cADPR content in islets in response to glucose stimulation. Furthermore, we determined the cADPR content by assessing the recovery of cADPR in the extraction and concentration procedures, but they did not. On the other hand, Malaisse et al. [44] incubated islets for a relatively longer period $(90 \mathrm{~min})$, whereas we incubated them for 5-40 min. In our experiment, the cADPR content in islets increased significantly within $10 \mathrm{~min}$ of incubation with high glucose but the small increase after 40 min incubation was not statistically significant compared with the cADPR content in islets incubated with low glucose. These differences in the experimental conditions may be responsible for the different results. We also isolated islets from $\mathrm{C} 57 \mathrm{BL} / 6 \mathrm{~J}$ mice, incubated them under low and high glucose conditions, and measured the cADPR content. The cADPR content was significantly increased by glucose stimulation. In $o b / o b$ mouse islets, a small amount of cADPR was detected when incubated under low glucose conditions but the cADPR content was not increased by high glucose. Furthermore, we examined the cADPR content of RINm5F cells. cADPR was not detectable in RINm5F cells even by glucose stimulation. We have already examined the effects of $\mathrm{CADPR}$ and $\mathrm{IP}_{3}$ on insulin secretion by using digitonin-permeabilized pancreatic islets of normal Wistar rats [15]. Both cADPR and $\mathrm{Ca}^{2+}$ induced insulin secretion, but $\mathrm{IP}_{3}$ did not. The combined addition of cADPR and $\mathrm{Ca}^{2+}$ did not induce significantly more insulin secretion than the addition of cADPR or $\mathrm{Ca}^{2+}$ alone. The cADPR-induced insulin secretion was inhibited by the addition of EGTA. The results so far described suggest that cADPR acts as a second messenger for $\mathrm{Ca}^{2+}$ release for insulin secretion in normal beta cells by glucose stimulation, but not in diabetic beta cells.

\section{cADPR metabolizing enzymes}

We and others have found that human [32, 45], mouse [46] and rat [47] CD38s have both ADP-ribosyl cyclase, synthesizing cADPR from $\mathrm{NAD}^{+}$, and cADPR 
hydrolase to produce ADP-ribose. We expressed human CD38 cDNA in Escherichia coli, purified the CD38 protein and confirmed that CD38 has both ADP-ribosyl cyclase and cADPR hydrolase activities [34]. We further found that millimolar concentrations of ATP markedly inhibited the cADPR hydrolase of CD38. Incubation of $\mathrm{CD} 38$ with $\mathrm{NAD}^{+}$in the presence of ATP led to an accumulation of cADPR in the incubation medium $[32,34]$. Examination of the ATP binding site using an ATP analogue, 5'-p-fluorosulfonylbenzoyladenosine (FSBA) revealed that FSBA bound to lysine 129 of CD38. The cADPR hydrolase activity of CD38 was shown to be inhibited by ATP in a competitive manner with cADPR [34]. Therefore, ATP, produced in the process of glucose metabolism, appears to compete with cADPR for lysine 129 to inhibit the cADPR hydrolase activity of CD38, thereby increasing the cADPR content in islets as described above (see also Fig. 2).

We prepared transgenic mice overexpressing CD38 in pancreatic beta cells by ligating the rat insulin promoter to human CD38 cDNA and microinjecting it into fertilized mouse eggs [33]. The transgenic mice secreted more insulin than normal mice in response to glucose concentrations. The cADPR hydrolase activity of CD38 in the transgenic islets was inhibited by millimolar concentrations of ATP. It should be noted here that, in the transgenic islets, $\alpha$ ketoisocaproate (KIC)-induced insulin secretion was also elevated compared with that in normal mouse islets. KIC, a deaminated metabolite of leucine, moves into the TCA cycle and rapidly produces ATP. However, tolbutamide and potassium chloride, which induce insulin secretion by promoting $\mathrm{Ca}^{2+}$ influx from extracellular sources, showed no significant difference in insulin secretion between transgenic and normal islets [33]. These results also provided further evidence for the contribution of the CD38-cADPR signal system to the release of $\mathrm{Ca}^{2+}$ from intracellular $\mathrm{Ca}^{2+}$ stores.

Kaisho et al. [48] found that the amino acid sequence of bone marrow stromal cell antigen 1 (BST1) had significant homology (33\% identity) with that of CD38. In an experiment using recombinant BST-1 protein, BST-1 showed only low enzymic activities of ADP-ribosyl cyclase and cADPR hydrolase in the presence of $\mathrm{Zn}^{2+}$ and $\mathrm{Mn}^{2+}$ or under acidic conditions [49], suggesting that BST-1 may play a role as a surface antigen rather than as an enzyme [50].

CD38 mRNA was detected in almost all human tissues, and especially high levels of the mRNA expression were observed in high glucose-utilizing tissues such as liver, kidney and brain [32]. We also cloned rat CD38 cDNA and determined the primary structure of the protein. Rat CD38 mRNA was expressed in pancreatic islets [47]. However, in RINm5F cells, rat insulinoma-derived immortal cells, which show almost no glucose-induced insulin secreting ability, CD38 mRNA was not expressed $[29,47,50]$. Furthermore, the CD38 mRNA level was significantly decreased in $o b / o b$ islets. The decreased CD38 mRNA in $o b / o b$ islets may explain the low response in cADPR content by glucose stimulation. Decreased CD38 mRNA was also reported in islets of Goto-Kakizaki (GK) diabetic rats [51], which show impaired glucose-induced insulin secretion [52].

CD38 was originally identified as a human leukocyte surface antigen and suggested to catalyse the enzymic activity at the extracellular domain. CD38 was however expressed not only in the plasma membrane but also in microsomal membrane fractions $[32,33]$. In addition, a cADPR metabolizing enzyme purified from canine spleen microsomes was identified as the canine homologue of CD38 [53], and an increase of the cADPR content in HL-60 cells corresponding to the induction of CD38 by retinoic acid was reported [43]. Our recent experiments indicated that the cADPR levels in CD38 cDNA-introduced RINm5F clones 1 and 3, RINm5F-derived cell lines into which CD38 had been introduced, were significantly higher than those of RINm5F cells, in which CD38 mRNA expression was not detected $[47,50]$.

We determined the nucleotide sequences of Aplysia kurodai ADP-ribosyl cyclase [54] and human CD38 genes [55]. Both genes contain 8 exons and 7 introns, and the exon-intron boundaries are wellconserved between both genes. Ten cysteine residues, which are conserved in the two genes and are thought to be essential for the enzyme activity, were coded to each corresponding exon [55]. It could be speculated that both genes have evolved from a common ancestral gene. We mapped the human CD38 gene to chromosome $4 p 15$ [56]. We have experimentally demonstrated that one amino acid mutation of CD38 causes a great change in the cADPR metabolizing enzyme activity of CD38 [34,57]. Thus, we searched for CD38 gene mutations in diabetic patients. In 100 non-insulin-dependent diabetic patients with insufficient insulin secretion and 90 control subjects, we amplified all 8 exons of the CD38 gene by PCR, screened the gene mutations by the single strand conformation polymorphism (SSCP) method and determined the sequences of the mutated gene. No mutation causing any amino acid change in CD38 was observed in the control group, but a gene mutation that caused the replacement of arginine 140 of CD38 by tryptophan was observed in four patients in the diabetes group. We actually expressed the mutated gene in COS-7 cells, measured the cADPR metabolizing enzyme activity and found that the enzyme activity (ADP-ribosyl cyclase/cADPR hydrolase) of the mutated protein was reduced to $40-50 \%$ of the normal CD38 activity [58]. 


\section{Mechanism of $\mathrm{Ca}^{2+}$ release by $c A D P R$}

As described above, cADPR is considered to mediate the release of $\mathrm{Ca}^{2+}$ from the endoplasmic reticulum by a mechanism different from that of $\mathrm{IP}_{3}$. The addition of ryanodine to islet microsomes caused $\mathrm{Ca}^{2+}$ release, while the addition of cADPR to ryanodine-treated microsomes did not [15]. These results suggested that the cADPR-mediated $\mathrm{Ca}^{2+}$ release was caused via the RyR in the endoplasmic reticulum. We expressed 3 types (type 1, 2, and 3) of rabbit RyRs in COS-7 cells to perform a binding experiment with cADPR, but it did not bind to any expressed channel protein. Therefore, cADPR appeared to act on RyR through some mediators to release $\mathrm{Ca}^{2+}$. RyRs have been purified from both skeletal and cardiac muscle [59, 60], and FK506 (an immunosuppressant)-binding protein 12 (FKBP12) and FK506-binding protein 12.6 (FKBP12.6) were co-purified with type 1 RyR from striated muscle and with type 2 RyR from cardiac muscle, respectively [61, 62]. FKBP12 and FKBP12.6 were shown to bind selectively to type 1 and type 2 RyR, respectively [63]. It was further reported that the type 1 RyR was activated by dissociation of FKBP12 from the RyR by the addition of FK506 to release $\mathrm{Ca}^{2+}$ [64]. Recently, we found that FK506 as well as cADPR induced the release of $\mathrm{Ca}^{2+}$ from islet microsomes [35]. After islet microsomes were treated with FK506, the $\mathrm{Ca}^{2+}$ release by cADPR from the microsomes was reduced. cADPR as well as FK506 bound to FKBP12.6, which we also found occurs naturally in islet microsomes. When islet microsomes were treated with cADPR, FKBP12.6 dissociated from the microsomes and moved to the supernatant, releasing $\mathrm{Ca}^{2+}$ from the intracellular stores. The microsomes that were then devoid of FKBP12.6 did not show $\mathrm{Ca}^{2+}$ release by cADPR. Our recent experiments indicated that type 2 RyR is expressed in rat and mouse islets $[35,36]$. From these results, it is strongly suggested that cADPR may be a ligand for FKBP12.6 in islet RyR and that, when cADPR binds to FKBP12.6 in islet microsome RyR and causes the dissociation of FKBP12.6 from the RyR to form FKBP12.6-cADPR complex, the channel activity of the RyR is thereby increased to release $\mathrm{Ca}^{2+}$ from the endoplasmic reticulum [35]. The fact that rat FKBP12.6 mRNA was not expressed in RINm5F cells [35] may also explain the negative $\mathrm{Ca}^{2+}$ release response to cADPR of RINm5F cells [37-39].

In sea urchin eggs, it was suggested that calmodulin directly interacts with RyR to enhance the cADPR-mediated $\mathrm{Ca}^{2+}$ release [20,21]. We found that calmodulin greatly sensitized and enhanced the cADPR-mediated $\mathrm{Ca}^{2+}$ release from islet microsomes [22]. Furthermore, inhibitors for calmodulin and $\mathrm{Ca}^{2+} /$ calmodulin-dependent protein kinase II (CaM kinase II) completely abolished the glucose-induced insulin secretion as well as the
cADPR-mediated and calmodulin-enhanced $\mathrm{Ca}^{2+}$ release. These results suggested that the enhancing effect of calmodulin is due to phosphorylation of RyR by CaM kinase II in islet microsomes [22]. As calmodulin can easily be diluted under whole cell patch conditions, the negative $\mathrm{Ca}^{2+}$ release responses to cADPR obtained by the whole cell patch technique [37-39] may be explained by the loss or lack of calmodulin in the patch. As described above, the RyR can also be activated by the dissociation of FKBP12.6. The interaction between the dissociation of FKBP12.6 from RyR and the phosphorylation of RyR by CaM kinase II remains to be elucidated.

\section{cADPR in other cells and future perspectives}

In this paper we have described a novel mechanism of insulin secretion, the CD38-cADPR signalling system (Fig.2). An increase in intracellular $\left[\mathrm{Ca}^{2+}\right]$, which then triggers insulin secretion, has conventionally been explained by the hypothesis put forth by Ashcroft et al. [5] of Oxford University, in which $\mathrm{Ca}^{2+}$ influx is provided by extracellular sources [5]. The present paper describes a novel mechanism of insulin secretion in which the $\mathrm{Ca}^{2+}$ release from the endoplasmic reticulum, an intracellular $\mathrm{Ca}^{2+}$ pool, induces insulin secretion. Rojas et al. [4] examined the $\mathrm{Ca}^{2+}$ influx from extracellular sources and the $\mathrm{Ca}^{2+}$ release from the intracellular pool in human beta cells, and showed that $42-75 \%$ of the increase in intracellular $\left[\mathrm{Ca}^{2+}\right]$ by glucose stimulation was due to the release of $\mathrm{Ca}^{2+}$ from the intracellular stores. Thus, the importance of $\mathrm{Ca}^{2+}$ release from the endoplasmic reticulum in insulin secretion by glucose has been recognized. In the CD38-cADPR signalling system, an abnormality in $\mathrm{Ca}^{2+}$ release from RyR may cause a decrease in insulin secretion, leading to the development and exacerbation of diabetes. As oral therapeutic agents for diabetes, sulfonylureas such as tolbutamide, which promotes $\mathrm{Ca}^{2+}$ influx from extracellular sources, have been used. As described above, the $\mathrm{Ca}^{2+}$ release from intracellular stores is also regarded as important in glucose-stimulated insulin secretion. Thus, agents promoting $\mathrm{Ca}^{2+}$ release from the endoplasmic reticulum may prove to be effective in treating diabetes.

$\mathrm{IP}_{3}$ has been considered to be a second messenger for intracellular $\mathrm{Ca}^{2+}$ mobilization [6]. As described in this paper, in normal pancreatic beta cells, cADPR acts on the endoplasmic reticulum to release $\mathrm{Ca}^{2+}$. In this case, it appears that cADPR binds to a protein, FKBP12.6, and dissociates the protein from RyR to release $\mathrm{Ca}^{2+}$. Recently, various physiological phenomena from animal to plant cells, in addition to those of pancreatic beta cells, become understandable in terms of the cADPR-mediated $\mathrm{Ca}^{2+}$ mobilization [15-29, 65]. The list could be longer. Thus, cells can utilize two major second messengers, $\mathrm{IP}_{3}$ and 
cADPR, for $\mathrm{Ca}^{2+}$ mobilization depending on the species of cells and differences in the cellular conditions, physiological or pathological, and perform a variety of cellular functions.

$\mathrm{Ca}^{2+}$-induced $\mathrm{Ca}^{2+}$ release (CICR) is an important physiological phenomenon observed first in skeletal muscle cells [66, 67]. Subsequently, CICR has become known as an important regulatory mechanism of intracellular $\left[\mathrm{Ca}^{2+}\right]$ in almost all cells. As described in this paper, CICR can be explained by a series of amplification processes in which CaM kinase II is activated by $\mathrm{Ca}^{2+}$ released from intracellular stores and/or supplied from extracellular sources, and the activated enzyme phosphorylates RyR to further release $\mathrm{Ca}^{2+}$ from the activated RyR (see also Fig.2). The fact that phosphorylation can be involved in the process of the CD38-cADPR signalling system suggests that this novel signalling system can be involved in long-term cell phenomena such as cell proliferation and plasticity of nerve cells, as well as relatively short-term physiological phenomena such as insulin secretion.

Note added in proof: Reference 36 is a review paper, experimental details of which will be published (Takasawa S, Akiyama T, Nata K et al. (1998) Cyclic ADP-ribose and inositol 1, 4, 5-trisphosphate as alternate second messengers for intracellular $\mathrm{Ca}^{2+}$ mobilization in normal and diabetic $\beta$-cells. J Biol Chem in press).

Acknowledgements. Work by the authors included in this review was supported by grants from the Ministry of Education, Science, Sports and Culture, Japan. The authors are grateful to Brent Bell for valuable assistance in preparing the manuscript.

\section{References}

1. Itoh N, Okamoto H (1980) Translational control of proinsulin synthesis by glucose. Nature 283: 100-102

2. Okamoto H (1981) Regulation of proinsulin synthesis in pancreatic islets and a new aspect to insulin-dependent diabetes. Mol Cell Biochem 37: 43-61

3. Hedeskov CJ (1980) Mechanism of glucose-induced insulin secretion. Physiol Rev 60: 442-509

4. Rojas E, Carroll PB, Ricordi C, Boschero AC et al. (1994) Control of cytosolic free calcium in cultured human pancreatic $\beta$-cells occurs by external calcium-dependent and independent mechanisms. Endocrinology 134: 1771-1781

5. Ashcroft FM, Harrison DE, Ashcroft SJH (1984) Glucose induced closure of single potassium channels in isolated rat pancreatic $\beta$-cells. Nature 312: 446-448

6. Berridge MJ, Irvine RF (1989) Inositol phosphate and cell signalling. Nature 341: 197-201

7. Yamamoto H, Uchigata Y, Okamoto H (1981) Streptozotocin and alloxan induce DNA strand breaks and poly(ADP-ribose) synthetase in pancreatic islets. Nature 294: 284-286

8. Uchigata Y, Yamamoto H, Kawamura A, Okamoto H (1982) Protection by superoxide dismutase, catalase, and poly(ADPribose) synthetase inhibitors against alloxan- and streptozotocin-induced islet DNA strand breaks and against the inhibition of proinsulin synthesis. J Biol Chem 257: 6084-6088

9. Uchigata Y, Yamamoto H, Nagai H, Okamoto H (1983) Effect of poly(ADP-ribose) synthetase inhibitor administration to rats before and after injection of alloxan and streptozotocin on islet proinsulin synthesis. Diabetes 32: 316-318

10. Okamoto H (1985) Molecular basis of experimental diabetes: degradation, oncogenesis, and regeneration of pancreatic Bcells of islets of Langerhans. BioEssays 2: 15-21

11. Okamoto H (1990) The molecular basis of experimental diabetes. In: Okamoto $\mathrm{H}$ (ed) Molecular biology of the islets of Langerhans. Cambridge University Press, Cambridge pp 209231

12. Okamoto H (1996) Okamoto model for B-cell damage: recent advances. In: Shafrir E (ed) Lessons from animal diabetes VI. Birkhäuser, Boston pp 97-111

13. Clapper DL, Walseth TF, Dargie PJ, Lee HC (1987) Pyridine nucleotide metabolites stimulate calcium release from sea urchin egg microsomes desensitized to inositol trisphosphate. J Biol Chem 262: 9561-9568

14. Lee HC, Walseth TF, Bratt GT et al. (1989) Structural determination of a cyclic metabolite of $\mathrm{NAD}^{+}$with intracellular $\mathrm{Ca}^{2+}$ mobilizing activity. J Biol Chem 264: 1608-1615

15. Takasawa S, Nata K, Yonekura H, Okamoto H (1993) Cyclic ADP-ribose in insulin secretion from pancreatic $\beta$ cells. Science 259: $370-373$

16. Galione A (1993) Cyclic ADP-ribose: a new way to control calcium. Science 259: 325-326

17. Sasaki T, Shimura S, Takasawa S et al. (1993) Cyclic ADP-ribose, a candidate for a novel $\mathrm{Ca}^{2+}$-mobilizing second messenger, induced $\mathrm{Ca}^{2+}$-dependent current responses in airway submucosal gland cells. Am Rev Resp Dis 147: A936

18. Hua S-Y, Tokimasa T, Takasawa S et al. (1994) Cyclic ADP-ribose modulates $\mathrm{Ca}^{2+}$ release channels for activation by physiological $\mathrm{Ca}^{2+}$ entry in bullfrog sympathetic neurons. Neuron 12 : 1073-1079

19. Thorn P, Gerashimenko P, Petersen OH (1994) Cyclic ADP-ribose regulation of ryanodine receptors involved in agonist evoked cytosolic $\mathrm{Ca}^{2+}$ oscillations in pancreatic acinar cells. EMBO J 13: 2038-2043

20. Lee HC, Aarhus R, Graeff R, Gurnack ME, Walseth TF (1994) Cyclic ADP ribose activation of the ryanodine receptor is mediated by calmodulin. Nature 370: 307-309

21. Tanaka Y, Tashjian AH Jr (1995) Calmodulin is a selective mediator of $\mathrm{Ca}^{2+}$-induced $\mathrm{Ca}^{2+}$ release via the ryanodine receptor-like $\mathrm{Ca}^{2+}$ channel triggered by cyclic ADP-ribose. Proc Natl Acad Sci USA 92: 3244-3248

22. Takasawa S, Ishida A, Nata K et al. (1995) Requirement of calmodulin-dependent protein kinase II in cyclic ADP-ribosemediated intracellular $\mathrm{Ca}^{2+}$ mobilization. J Biol Chem 270: 30257-30259

23. Higashida H, Robbins J, Egorova A et al. (1995) Nicotinamideadenine dinucleotide regulates muscarinic receptor-coupled $\mathrm{K}^{+}(\mathrm{M})$ channels in rodent NG108-15 cells. J Physiol (London) 482: $317-323$

24. Allen GJ, Muir SR, Sanders D (1995) Release of $\mathrm{Ca}^{2+}$ from individual plant vacuoles by both $\mathrm{InsP}_{3}$ and cyclic ADP-ribose. Science 268: 735-737

25. Kuemmerle JF, Makhlouf GM (1995) Agonist-stimulated cyclic ADP ribose: endogenous modulator of $\mathrm{Ca}^{2+}$-induced $\mathrm{Ca}^{2+}$ release in intestinal longitudinal muscle. J Biol Chem 270: 25488-25494

26. Gromada J, Jørgensen TD, Dissing S (1995) Cyclic ADP-ribose and inositol 1,4,5-trisphosphate mobilizes $\mathrm{Ca}^{2+}$ from distinct intracellular pools in permeabilized lacrimal acinar cells. FEBS Lett 360: 303-306

27. Sitsapesan R, Williams AJ (1995) Cyclic ADP-ribose and related compounds activate sheep skeletal sarcoplasmic reticulum $\mathrm{Ca}^{2+}$ release channel. Am J Physiol 268: C1235-C1240

28. Rakovic S, Galione A, Ashamu GA, Potter BVL, Terrar DA (1996) A specific cyclic ADP-ribose antagonist inhibits cardiac excitation-contraction coupling. Curr Biol 6: 989-996

29. Ebihara S, Sasaki T, Hida W et al. (1997) Role of cyclic ADP-ribose in ATP-activated potassium currents in alveolar macrophages. J Biol Chem 272: 16023-16029 
30. Okamoto H, Takasawa S, Tohgo A (1995) New aspects of the physiological significance of NAD, poly ADP-ribose and cyclic ADP-ribose. Biochimie 77: 356-363

31. Okamoto H, Takasawa S, Tohgo A, Nata K, Kato I, Noguchi N (1997) Synthesis and hydrolysis of cyclic ADP-ribose by human leukocyte antigen CD38: inhibition of hydrolysis by ATP and the physiological significance. Meth Enzymol 280: 306-318

32. Takasawa S, Tohgo A, Noguchi N et al. (1993) Synthesis and hydrolysis of cyclic ADP-ribose by human leukocyte antigen CD38 and inhibition of the hydrolysis by ATP. J Biol Chem 268: 26052-26054

33. Kato I, Takasawa S, Akabane A et al. (1995) Regulatory role of CD38 (ADP-ribosyl cyclase/cyclic ADP-ribose hydrolase) in insulin secretion by glucose in pancreatic $\beta$ cells. Enhanced insulin secretion in CD38-expressing transgenic mice. J Biol Chem 270: 30045-30050

34. Tohgo A, Munakata H, Takasawa S et al. (1997) Lysine 129 of CD38 (ADP-ribosyl cyclase/cyclic ADP-ribose hydrolase) participates in the binding of ATP to inhibit the cyclic ADP-ribose hydrolase. J Biol Chem 272: 3879-3882

35. Noguchi N, Takasawa S, Nata K et al. (1997) Cyclic ADP-ribose binds to FK506-binding protein 12.6 to release $\mathrm{Ca}^{2+}$ from islet microsomes. J Biol Chem 272: 3133-3136

36. Okamoto H (1997) The CD38-cyclic ADP-ribose signaling system in insulin secretion. Mol Cell Biochem (in press)

37. Islam MS, Larsson O, Berggren P-O (1993) Cyclic ADP-ribose in $\beta$ cells. Science 262: $584-585$

38. Rutter GA, Theler J-M, Wollheim CB (1994) $\mathrm{Ca}^{2+}$ stores in insulin-secreting cells: lack of effect of cADP ribose. Cell Calcium 16: $71-80$

39. Webb D-L, Islam MS, Efanov AM et al. (1996) Insulin exocytosis and glucose-mediated increase in cytoplasmic free $\mathrm{Ca}^{2+}$ concentration in the pancreatic $\beta$-cell are independent of cyclic ADP-ribose. J Biol Chem 271: 19074-19079

40. Walseth TF, Lee HC (1993) Synthesis and characterization of antagonists of cyclic-ADP-ribose-induced $\mathrm{Ca}^{2+}$ release. Biochim Biophys Acta 1178: 235-242

41. Mészáros LG, Bak J, Chu A (1993) Cyclic ADP-ribose as an endogenous regulator of the non-skeletal type ryanodine receptor $\mathrm{Ca}^{2+}$ channel. Nature 364: 76-79

42. Blondel O, Takeda J, Janssen H, Seino S, Bell GI (1993) Sequence and functional characterization of a third inositol trisphosphate receptor subtype, IP3R-3, expressed in pancreatic islets, kidney, gastrointestinal tract, and other tissues. J Biol Chem 268: 11356-11363

43. Takahashi K, Kukimoto I, Tokita KI et al. (1995) Accumulation of cyclic ADP-ribose measured by a specific radioimmunoassay in differentiated human leukemic HL-60 cells with alltrans-retinoic acid. FEBS Lett 371: 204-208

44. Malaisse WJ, Kanda Y, Inageda K, Scruel O, Sener A, Katada $\mathrm{T}$ (1997) Cyclic ADP-ribose measurements in rat pancreatic islets. Biochem Biophys Res Commun 231: 546-548

45. Zocchi E, Frano L, Guida L et al. (1993) A single protein immunologically identified as CD38 displays NAD ${ }^{+}$glycohydrolase, ADP-ribosyl cyclase and cyclic ADP-ribose hydrolase activities at the outer surface of human erythrocytes. Biochem Biophys Res Commun 196: 1459-1465

46. Howard M, Grimaldi JC, Bazan JF et al. (1993) Formation and hydrolysis of cyclic ADP-ribose catalyzed by lymphocyte antigen CD38. Science 262: 1056-1059

47. Koguma T, Takasawa S, Tohgo A et al. (1994) Cloning and characterization of cDNA encoding rat ADP-ribosyl cyclase/ cyclic ADP-ribose hydrolase (homologue of human CD38) from islets of Langerhans. Biochim Biophys Acta 1223: 160162

48. Kaisho T, Ishikawa J, Oritani K et al. (1994) BST-1, a surface molecule of bone marrow stromal cell lines that facilitates pre B-cell growth. Proc Natl Acad Sci USA 91: 5325-5329

49. Hirata Y, Kimura N, Sato K et al. (1994) ADP ribosyl cyclase activity of a novel bone marrow stromal cell surface molecule, BST-1. FEBS Lett 356: 244-248
50. Furuya Y, Takasawa S, Yonekura H et al. (1995) Cloning of a cDNA encoding rat bone marrow stromal cell antigen 1 (BST1) from the islets of Langerhans. Gene 165: 329-330

51. Matsuoka T, Kajimoto Y, Watada H et al. (1995) Expression of CD38 gene, but not of mitochondrial glycerol-3-phosphate dehydrogenase gene, is impaired in pancreatic islets of GK rats. Biochem Biophys Res Commun 214: 239-246

52. Goto Y, Kakizaki M, Masaki N (1975) Spontaneous diabetes produced by selective breeding of normal Wistar rats. Proc Jpn Acad 51: 80-85

53. Jacobson MK, Amé J-C, Lin W, Coyle DL, Jacobson EL (1995) Cyclic ADP-ribose: a new component of calcium signaling. Receptor 5: 43-49

54. Nata K, Sugimoto T, Tohgo A et al. (1995) The structure of the Aplysia kurodai gene encoding ADP-ribosyl cyclase, a secondmessenger enzyme. Gene 158: 213-218

55. Nata K, Takamura T, Karasawa Tet al. (1997) Human gene encoding CD38 (ADP-ribosyl cyclase/cyclic ADP-ribose hydrolase): organization, nucleotide sequence and alternative splicing. Gene 186: 285-292

56. Nakagawara K, Mori M, Takasawa S et al. (1995) Assignment of CD38, the gene encoding human leukocyte antigen CD38 (ADP-ribosyl cyclase/cyclic ADP-ribose hydrolase), to chromosome 4p15. Cytogenet Cell Genet 69: 38-39

57. Tohgo A, Takasawa S, Noguchi N et al. (1994) Essential cysteine residues for cyclic ADP-ribose synthesis and hydrolysis by CD38. J Biol Chem 269: 28555-28557

58. Yagui K, Shimada F, Miura M et al. (1997) CD38 gene Arg140Trp mutation in Japanese subjects with NIDDM. Diabetes 46: 174A (Abstract)

59. Inui M, Saito A, Fleischer S (1987) Purification of the ryanodine receptor and identity with feet structures of junctional terminal cisternae of sarcoplasmic reticulum from fast skeletal muscle. J Biol Chem 262: 1740-1747

60. Inui M, Saito A, Fleischer S (1987) Isolation of the ryanodine receptor from cardiac sarcoplasmic reticulum and identity with the feet structures. J Biol Chem 262: 15637-15642

61. Jayaraman T, Brillantes A-M, Timerman AP et al. (1992) FK506 binding protein associated with the calcium release channel (ryanodine receptor). J Biol Chem 267: 9474-9477

62. Timerman AP, Jayaraman T, Wiederrecht G et al. (1994) The ryanodine receptor from canine heart sarcoplasmic reticulum is associated with a novel FK-506 binding protein. Biochem Biophys Res Commun 198: 701-706

63. Timerman AP, Onoue H, Xin H-B et al. (1996) Selective binding of FKBP12.6 by the cardiac ryanodine receptor. J Biol Chem 271: 20385-20391

64. Brillantes A-MB, Ondrias K, Scott A et al. (1994) Stabilization of calcium release channel (ryanodine receptor) function by FK506-binding protein. Cell 77: 513-523

65. Higashida H, Yokoyama S, Hashii M et al. (1997) Muscarinic receptor-mediated dual regulation of ADP-ribosyl cyclase in NG108-15 neuronal cell membranes analyzed by thin layer chromatography. J Biol Chem (in press)

66. Endo M, Tanaka M, Ogawa Y (1970) Calcium induced release of calcium from the sarcoplasmic reticulum of skinned muscle fibre. Nature 249: 469-475

67. Ford LE, Podolsky RJ (1970) Regenerative calcium release within muscle cells. Science 167: 58-59

68. Okamoto H Sr (1976) Antitumor activity of streptolysin Sforming streptococci. In: Bernheimer AW (ed). Mechanisms in bacterial toxinology. John Wiley \& Sons, New York pp 237257

69. Toyota T, Satoh J, Oya K, Shintani S, Okano T (1986) Streptococcal preparation (OK-432) inhibits development of type I diabetes in NOD mice. Diabetes 35: 496-499

70. Inagaki N, Gonoi T, Clement IV, JP et al. (1995) Reconstitution of $I_{\text {KATP: }}$ an inward rectifier subunit plus the sulfonylurea receptor. Science 270: 1166-1170 